\title{
Evaluasi Kelayakan Investasi Teknologi Informasi Menggunakan Metode Cost Benefit Analysis
}

\author{
Heni Sulistiani ${ }^{1)}$, Prita Dellia ${ }^{2)}$ \\ 1) STMIK Teknokrat Lampung, Jl. Z.A. Pagar Alam No. 9-11 Bandarlampung, (0721) 702022 \\ ${ }^{2)}$ Institut Teknologi Sepuluh Nopember, Jl. Raya ITS Sukolilo, Surabaya, (031) 5927939 \\ e-mail: henie.tekno@gmail.com, pritadellia@gmail.com
}

\begin{abstract}
Abstrak
Persaingan bisnis menuntut perusahaan untuk merumuskan suatu strategi jangka panjang dan jangka pendek yang tepat agar dapat mempertahankan kelangsungan hidup perusahaan. Banyak perusahaan yang menginvestasikan dananya untuk membangun teknologi informasi dan tiap tahun mengalami peningkatan dalam investasi teknologi informasi pada perusahaan. Saat melakukan investasi, suatu instansi harus mengetahui faktor-faktor yang menyebabkan kegagalan dalam proyek teknologi informasi. Oleh karena itu, diperlukan suatu strategi investasi yang dapat menjamin bahwa investasi yang akan dilakukan sesuai dengan kebutuhan organisasi serta sejalan dengan visi dan misi instansi terkait. Hal ini dikarenakan sulitnya mengukur nilai keuntungan ekonomis yang dihasilkan dari sebuah sistem informasi manajemen karena yang dihasilkan lebih berupa peningkatan kinerja operasional perusahaan yang sifatnya intangible. Tujuan penelitian ini adalah melakukan analisis pengukuran dan evaluasi teknologi informasi menggunakan metode cost and benefit analysis pada ARM Solusi Kota Surabaya, agar dapat memberikan pertimbangan atas manfaat yang dihasilkan dari investasi penggunaan teknologi informasi.
\end{abstract}

Kata kunci: cost benefit analysis, evaluasi, net present value, teknologi informasi

\section{Pendahuluan}

Keberadaan dan peranan teknologi informasi (TI) di segala sektor kehidupan tanpa sadar telah membawa dunia memasuki era baru globalisasi lebih cepat dari yang kita bayangan [1]. Kini, teknologi informasi tidak hanya digunakan untuk proses operasional sehari-hari, tetapi juga dapat memberikan keuntungan yang kompetitif bagi organisasi dan dapat digunakan sebagai alat pertukaran informasi [2]. Pada iklim bisnis yang semakin kompleks dan ketat seperti saat ini, perusahaan tidak dapat lagi menghasilkan keunggulan kompetitif (competitive advantage) yang berkesinambungan hanya dengan menerapkan TI baru ke dalam kegiatan perusahaan secara cepat [3]. Kondisi persaingan bisnis ternyata menuntut perusahaan untuk merumuskan suatu strategi jangka panjang dan jangka pendek yang tepat agar dapat mempertahankan kelangsungan hidup perusahaan.

Sebuah instansi atau perusahaan kini telah percaya bahwa teknologi informasi mampu membantu mengembangkan dan memajukan operasi di instansi atau perusahaan tersebut. Maka mereka bersedia menyediakan anggaran untuk berinvestasi teknologi demi memperoleh nilai tambah pada organisasinya [4]. Banyak perusahaan yang menginvestasikan dananya untuk membangun teknologi informasi dan tiap tahun mengalami peningkatan dalam investasi teknologi informasi pada perusahaan. Saat melakukan investasi TI, suatu instansi harus mengetahui faktor-faktor yang menyebabkan kegagalan dalam proyek TI. Oleh karena itu, diperlukan suatu strategi investasi TI yang dapat menjamin bahwa investasi yang akan dilakukan sesuai dengan kebutuhan organisasi serta sejalan dengan visi dan misi instansi terkait [2]. Investasi teknologi informasi merupakan keputusan yang diambil oleh organisasi untuk meningkatkan sumber daya dari pengeluaran biaya yang nyata dari teknologi informasi dengan harapan manfaat dari pengeluaran tersebut mencapai nilai dari apa yang diharapkan [5]. Efektifitas penggunaan sistem informasi manajemen secara umum memang sulit untuk diidentifikasi [6], hal ini dikarenakan pengembangan sistem informasi manajemen yang biasanya menyita banyak investasi perusahaan, ternyata tidak bisa memberikan kepastian pengembalian hasil yang nyata secara ekonomis.

ARM Solusi merupakan sebuah organisasi yang bergerak di bidang jasa konsultan TI dengan memanfaatkan TI dalam proses bisnisnya. Salah satu aplikasi yang digunakan adalah aplikasi project management untuk memantau dan mempermudah koordinasi dalam penyelesaian tugas masing-masing 
anggota tim proyek. Namun, investasi untuk implementasi TI saat ini menghabiskan biaya yang tidak sedikit dengan tingkat pengembalian yang kadang tidak terlihat dan sulit diukur benefitnya [3]. Selain itu, perusahaan seringkali kesulitan dalam mengidentifikasi, menganalisa dan mengontrol biaya TI. Kecenderungan untuk menekan biaya investasi TI setiap tahunnya menyebabkan kompromi dalam memilih atau mengembangkan TI yang tidak sesuai dengan kapabilitas yang dibutuhkan.

Secara umum memang sulit untuk mengukur secara ekonomis tingkat pengembalian hasil dari suatu investasi pengembangan sistem informasi manajemen, hal ini lebih dikarenakan sulitnya mengukur nilai keuntungan ekonomis yang dihasilkan dari sebuah sistem informasi manajemen karena yang dihasilkan lebih berupa peningkatan kinerja operasional perusahaan yang sifatnya intangible. Salah satu metode yang digunakan untuk melakukan pengukuran investasi TI terhadap pengembalian hasil secara ekonomis adalah cost and benefit analysis. Metode tersebut digunakan untuk menentukan atau menghitung nilai dari setiap elemen teknologi informasi yang memiliki kontribusi terhadap biaya yang dikeluarkan dan manfaat yang diperoleh. Analisis kelayakan ekonomis dilakukan dengan memanfaatkan alat analisis finansial yang ada, seperti net present value (NPV). Dari hasil analisis tersebut, dapat memberikan pertimbangan atas manfaat yang dihasilkan dari investasi penggunaan aplikasi project management.

\section{Metode Penelitian}

Jenis penelitian yang dilakukan adalah deskriptif kuantitatif, dengan pendekatan studi kasus untuk melacak kejadian-kejadian yang pernah terjadi guna memperoleh informasi mengenai penggunaan aplikasi project management pada ARM Solusi Kota Surabaya. Data yang dikumpulkan terdiri dari data primer, mengenai data biaya-biaya yang tergolong unsur biaya (cost) dan unsur manfaat (benefit), dan data sekunder yang berisi data-data nominal yang diperoleh dari hasil studi dokumentasi. Teknik pengumpulan data pada penelitian ini yaitu pada pengumpulan data primer dilakukan dengan cara wawancara dan observasi, sedangkan untuk pengumpulan data sekunder dilakukan dengan cara studi dokumentasi pada laporan keuangan dan dokumen-dokumen lain. Teknik penyajian data dalam bentuk tabel yang disertai dengan penjelasan (tekstular). Analisis data dilakukan dengan mengacu pada perhitungan Cost Benefit Analysis. Secara umum, rangkaian tahapan penelitian digambarkan pada gambar 1.

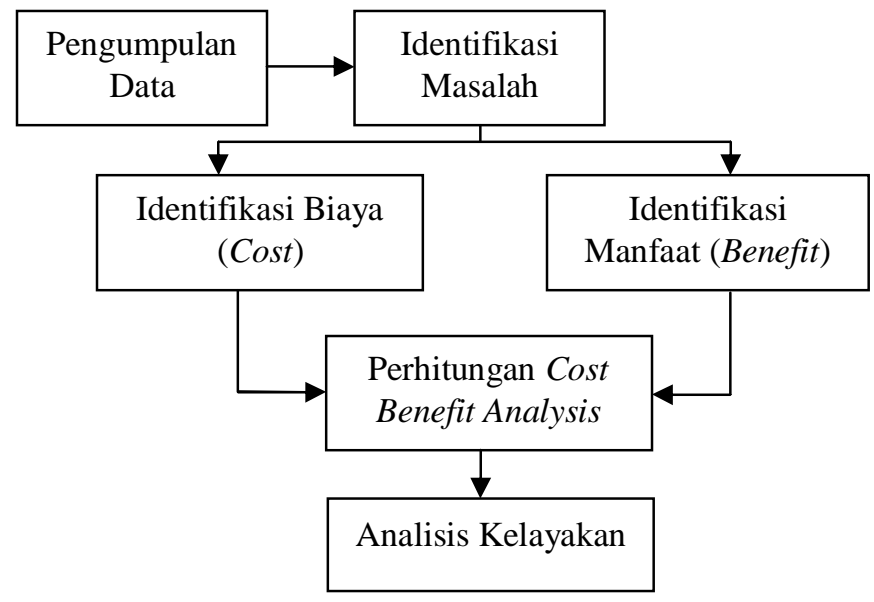

Gambar 1 Tahapan Penelitian

\section{Hasil dan Pembahasan}

\subsection{Identifikasi Biaya}

Hasil dari identifikasi unsur biaya (cost) yang harus dikeluarkan perusahaan dalam membangun dan menjalankan aplikasi project management antara lain biaya pengadaan, biaya start up, biaya proyek dan biaya penerapan. Biaya ini merupakan bentuk pengorbanan yang dikeluarkan perusahaan untuk mendapatkan manfaat yang maksimal. Biaya pengadaan (procurement cost) merupakan total semua biaya pengadaan hardware yang diinvestasikan untuk menunjang kebutuhan bisnis. Tabel 1 menunjukkan biaya pengadaan yang dikeluarkan oleh ARM Solusi pada tahun pertama pendirian perusahaan.

Biaya Start Up merupakan biaya yang harus dikeluarkan untuk mendukung kebutuhan operasional. Tabel 2 menunjukkan daftar biaya Start Up pada ARM Solusi. Biaya proyek (Project Related Cost) adalah total biaya yang harus dikeluarkan pada saat mengembangkan sistem termasuk biaya 
penerapannya. Tabel 3 menunjukkan biaya proyek yang dikeluarkan oleh ARM Solusi. Sedangkan biaya penerapan (ongoing cost) merupakan biaya yang dikeluarkan pada saat proyek atau aplikasi telah diterapkan. Tabel 4 menunjukkan daftar ongoing cost yang dikeluarkan oleh ARM Solusi.

Tabel 1 Daftar Biaya Pengadaan

\begin{tabular}{|c|l|lr|}
\hline No & \multicolumn{1}{|c|}{ Nama Kebutuhan } & \multicolumn{2}{c|}{ Biaya } \\
\hline 1 & AC (1 Unit) & $\mathrm{Rp}$ & $3,000,000$ \\
\hline 2 & Modem ( 1 Unit) & $\mathrm{Rp}$ & 250,000 \\
\hline 3 & Switch & $\mathrm{Rp}$ & 300,000 \\
\hline 4 & Glass Board (1 Unit) & $\mathrm{Rp}$ & 750,000 \\
\hline 5 & White Board (3 Unit) & $\mathrm{Rp}$ & 900,000 \\
\hline 6 & HP Motto E (7 unit) & $\mathrm{Rp}$ & $1,300,000$ \\
\hline 7 & Proyektor Sony SvGa VPL-ES5 (1 unit) & $\mathrm{Rp}$ & $10,125,000$ \\
\hline 8 & Printer Epson L100 (1 unit) & $\mathrm{Rp}$ & $1,250,000$ \\
\hline 9 & TV Sams ung 32 Inch (1 unit) & $\mathrm{Rp}$ & $5,000,000$ \\
\hline 10 & Sound Advance Digital & $\mathrm{Rp}$ & 500,000 \\
\hline 11 & Modem Motorola sb5101 & $\mathrm{Rp}$ & 250,000 \\
\hline 12 & Wifi Linksys seri e1000 & $\mathrm{Rp}$ & 500,000 \\
\hline 13 & Kipas Angin & $\mathrm{Rp}$ & 215,000 \\
\hline 14 & Monitor BenQ 17 inch & $\mathrm{Rp}$ & 970,000 \\
\hline 15 & Mikrotik Router & $\mathrm{Rp}$ & 569,000 \\
\hline 16 & Paper Shredder Krisbow S320 & $\mathrm{Rp}$ & $1,200,000$ \\
\hline & Total Biaya Pengadaan & $\mathrm{Rp}$ & $27,079,000$ \\
\hline
\end{tabular}

Tabel 2 Daftar Biaya Start Up

\begin{tabular}{|c|l|lr|}
\hline No & \multicolumn{1}{|c|}{ Nama Kebutuhan } & \multicolumn{2}{|c|}{ Biaya } \\
\hline 1 & Pembelian Software Mikrotik & $\mathrm{Rp}$ & 930,000 \\
\hline 2 & Biaya Perlengkapan & $\mathrm{Rp}$ & 500,000 \\
\hline 3 & Biaya Manajemen SDM & $\mathrm{Rp}$ & $10,000,000$ \\
\hline 4 & Biaya Internet & $\mathrm{Rp}$ & $5,820,000$ \\
\hline \multicolumn{2}{|c|}{ Total Biaya Start $\boldsymbol{U p}$} & $\mathrm{Rp}$ & $17,250,000$ \\
\hline
\end{tabular}

Tabel 3 Daftar Biaya Proyek

\begin{tabular}{|c|l|lr|}
\hline No & \multicolumn{2}{|c|}{ Nama Kebutuhan } & \multicolumn{2}{c|}{ Biaya } \\
\hline 1 & Sewa VPS dan domain & $\mathrm{Rp}$ & $2,000,000$ \\
\hline 2 & Biaya Dokumentasi & $\mathrm{Rp}$ & $3,600,000$ \\
\hline \multicolumn{2}{|c|}{ Total Biaya Proyek } & $\mathrm{Rp}$ & $5,600,000$ \\
\hline
\end{tabular}

Tabel 4 Daftar Ongoing Cost

\begin{tabular}{|c|c|c|c|c|c|c|c|c|c|c|}
\hline No & $\begin{array}{c}\text { Nama } \\
\text { Kebutuhan }\end{array}$ & Th 0 & & Th 1 & & Th 2 & & Th 3 & & Th 4 \\
\hline 1 & \begin{tabular}{|l|} 
Gaji \\
Karyawan \\
\end{tabular} & - & $\mathrm{Rp}$ & 180.000 .000 & $\mathrm{Rp}$ & 189.000.000 & $\mathrm{Rp}$ & 198.450 .000 & $\mathrm{Rp}$ & 208.372 .500 \\
\hline 2 & ATK & - & $\mathrm{Rp}$ & 3.600 .000 & $\mathrm{Rp}$ & 3.600 .000 & $\mathrm{Rp}$ & 3.780 .000 & $\mathrm{Rp}$ & 3.969 .000 \\
\hline 3 & \begin{tabular}{|l} 
Biaya \\
Perawatan \\
Hardware \\
\end{tabular} & - & $\mathrm{Rp}$ & 5.000 .000 & Rp & 5.000 .000 & $\mathrm{Rp}$ & 5.250 .000 & $\mathrm{Rp}$ & 5.512 .500 \\
\hline 4 & $\begin{array}{l}\text { Biaya } \\
\text { Perawatan } \\
\text { Software }\end{array}$ & - & $\mathrm{Rp}$ & 3.000 .000 & $\mathrm{Rp}$ & 3.000 .000 & $\mathrm{Rp}$ & 3.150 .000 & $\mathrm{Rp}$ & 3.307 .500 \\
\hline 5 & \begin{tabular}{|l|} 
Biaya \\
Perawatan \\
Perlengkapa \\
n \& Fasilitas \\
\end{tabular} & - & $\mathrm{Rp}$ & 5.000 .000 & $\mathrm{Rp}$ & 5.000 .000 & $\mathrm{Rp}$ & 5.250 .000 & $\mathrm{Rp}$ & 5.512 .500 \\
\hline 6 & Biaya Listrik & - & $\mathrm{Rp}$ & 6.000 .000 & $\mathrm{Rp}$ & 6.000 .000 & $\mathrm{Rp}$ & 6.300 .000 & $\mathrm{Rp}$ & 6.615 .000 \\
\hline \multicolumn{2}{|c|}{ Total Ongoing } & & $\mathrm{Rp}$ & 202.600 .000 & $\mathrm{Rp}$ & 211.600 .000 & $\mathrm{Rp}$ & 222.180 .000 & $\mathrm{Rp}$ & 233.289 .000 \\
\hline
\end{tabular}

L-2 Evaluasi Investasi Teknologi Informasi M enggunakan M etode Cost and Benefit Analysis (Heni Sulistiani) 
Berdasarkan data unsur biaya pada tahun ke 0 dan dilakukan analisis selama 5 tahun, tiap tahunnya mengalami kenaikan unsur biaya mengikuti kenaikan nilai tukar rupiah terhadap dollar ataupun kenaikan laju inflasi rupiah. Seluruh biaya diasumsikan mengalami kenaikan sebesar 5\% yang mengacu pada kenaikan inflasi pada bulan Januari 2013 hingga Nopember 2015 yang berkisar 5\% per tahun.

\subsection{Identifikasi Manfaat}

Identifikasi unsur manfaat (benefit) bertujuan untuk mengetahui manfaat yang didapat dari implementasi aplikasi project management pada ARM Solusi. Manfaat dibedakan menjadi manfaat berwujud (tangible) dan yang tidak berwujud (intangible). Analisis manfaat berwujud dilakukan dengan empat metode pendekatan, yaitu cost displacement, cost avoidance, decision analysis dan impact analysis. Hasil analisis manfaat berwujud diuraikan pada tabel 5.

Tabel 5 Total Manfaat Berwujud

\begin{tabular}{|c|c|c|c|}
\hline No & Manfaat Berwujud & & Total \\
\hline \multirow[t]{7}{*}{1} & Cost Displacement & & \\
\hline & - Pengurangan Biaya Tinta & $\mathrm{Rp}$ & 2.480 .000 \\
\hline & - Pengurangan Biaya Kertas & $\mathrm{Rp}$ & 1.200 .000 \\
\hline & - Pengurangan Biaya Telepon/Pulsa & $\mathrm{Rp}$ & 10.500 .000 \\
\hline & - Pengurangan Biaya Spidol & $\mathrm{Rp}$ & 132.000 \\
\hline & - Pengurangan biaya tinta spidol & $\mathrm{Rp}$ & 650.000 \\
\hline & Total Manfaat Cost Displacement & $\mathbf{R p}$ & 14.962 .000 \\
\hline \multirow[t]{3}{*}{2} & \multicolumn{3}{|l|}{ Cost Avoidance } \\
\hline & $\begin{array}{l}\text { Penghilangan biaya karyawan untuk kegiatan } \\
\text { pelaporan pelaksanaan/pengerjaan proyek dan kinerja }\end{array}$ & $\mathrm{Rp}$ & 8.320 .000 \\
\hline & Total Manfaat Cost Avoidance & $\mathbf{R p}$ & 8.320 .000 \\
\hline \multirow[t]{3}{*}{3} & \multicolumn{3}{|l|}{ Decision Analysis } \\
\hline & Pembayaran piutang lebih cepat atau tepat waktu & $\mathrm{Rp}$ & 90.000 .000 \\
\hline & Total Manfaat Decision Analysis & $\mathbf{R p}$ & 90.000 .000 \\
\hline \multirow[t]{4}{*}{4} & \multicolumn{3}{|l|}{ Impact Analysis } \\
\hline & - $\quad$ Percepatan waktu dalam pencarian dokumen & $\mathrm{Rp}$ & 2.340 .000 \\
\hline & $\begin{array}{l}\text { - Penghematan waktu pengontrolan pelaksanaan } \\
\text { pengerjaan proyek }\end{array}$ & $\mathrm{Rp}$ & 720.000 \\
\hline & Total Manfaat Impact Analysis & $\mathbf{R p}$ & 3.060.000 \\
\hline \multicolumn{2}{|c|}{ Total Manfaat Berwujud } & $\mathbf{R p}$ & 116.342.000 \\
\hline
\end{tabular}

Sedangkan manfaat tidak berwujud terdiri dari peningkatan motivasi karyawan, peningkatan moral kerja karyawan dan pelayanan yang lebih baik kepada klien. Berdasarkan hasil wawancara dengan pihak ARM Solusi, manfaat tidak berwujud yang diperoleh dari implementasi aplikasi project management antara lain peningkatan motivasi karyawan atau anggota tim yang berdampak pada produktivitas karyawan, peningkatan moral kerja karyawan yang berdampak pada pengurangan kecurangan atau ketidakjujuran karyawan. Keuntungan tidak berwujud mempunyai sumbangsih yang cukup besar bagi perusahaan, sehingga manfaat tidak berwujud harus tetap diperhatikan walaupun sulit diukur dalam bentuk satuan nilai uang. Berikut adalah penjelasan dari manfaat tidak berwujud yang diperoleh ARM Solusi:

a) Peningkatan produktivitas karyawan

Adanya aplikasi project management memberikan kemudahan bagi para karyawan sehingga mereka merasa termotivasi dalam menyelesaikan tugas dan tanggung jawabnya. Dengan adanya peningkatan motivasi karyawan, produktivitas karyawan menjadi bertambah sehingga pekerjaan dapat diselesaikan lebih cepat. Peningkatan produktivitas karyawan ini dapat diukur dengan menggunakan penaksiran bersama pihak perusahaan dengan menetapkan persentase kemungkinan peningkatannya. Berikut adalah hasil penaksirannya:

(1) Kemungkinan 50\% karyawan produktivitasnya bertambah $30 \%$

(2) Kemungkinan 30\% karyawan produktivitasnya bertambah $60 \%$ 
(3) Kemungkinan $20 \%$ karyawan produktivitasnya bertambah $90 \%$

Selanjutnya dihitung perkiraan peningkatan produktivitas karyawan sebagai berikut:

Peningkatan Produktivitas $\quad=(50 \%$ x 30\% $)+(30 \% \times 60 \%)+(20 \% \times 90 \%)$

$=(15 \%+18 \%+18 \%)$

$=51 \%$

Jika rata-rata gaji karyawan tiap tahun sebesar Rp. 60.000.000,- maka dapat diperkirakan perusahaan akan mendapatkan keuntungan sebesar 51\% dari nilai gaji karyawan sebesar Rp. 30.600.000,-. Jika pada ARM Solusi memiliki 6 karyawan dalam pengelolaan proyek, maka jumlah penghematan dari adanya peningkatan produktivitas karyawan adalah sebesar Rp. 183.600.000,-.

b) Peningkatan moral kerja karyawan

Adanya aplikasi project management dapat mengurangi terjadinya kecurangan atau ketidakjujuran karyawan dalam hal saling lempar tanggung jawab, sehingga dapat mengurangi kerugian akibat kecurangan karyawan. Dengan berkurangnya kecurangan karyawan, menandakan bahwa moral kerja karyawan meningkat. Peningkatan moral kerja ini dapat diukur dengan menggunakan penaksiran bersama pihak perusahaan dengan menetapkan persentase kemungkinan peningkatannya. Berikut adalah hasil penaksirannya:

(1) Kemungkinan $60 \%$ karyawan moral kerja meningkat $30 \%$

(2) Kemungkinan 30\% karyawan moral kerja meningkat 50\%

(3) Kemungkinan $10 \%$ karyawan moral kerja meningkat $90 \%$

Selanjutnya dihitung perkiraan peningkatan moral kerja karyawan sebagai berikut:

Peningkatan moral kerja $\quad=(60 \% \times 30 \%)+(30 \% \times 50 \%)+(10 \% \times 90 \%)$

$=(18 \%+15 \%+9 \%)$

$=42 \%$

Jika rata-rata perkiraan kecurangan yang dilakukan karyawan, seperti saling lempar tanggung jawab, yang akan menyebabkan waktu pengerjaan proyek akan tertunda. Sedangkan pembayaran piutang akan tertunda selama proyek belum selesai, diperkirakan jumlah piutang yang tertunda akibat kecurangan tersebut adalah sebesar Rp. 90.000.000,- selama satu tahun. Maka dapat diperkirakan perusahaan akan mendapatkan keuntungan sebesar $42 \%$ dari nilai penundaan pembayaran piutang sebesar Rp. 37.800.000,-

Hasil dari analisis manfaat tidak berwujud yang diperoleh yaitu peningkatan produktivitas karyawan dan peningkatan moral karyawan dapat dilihat pada tabel 6.

Tabel 6 Total Manfaat Tidak Berwujud

\begin{tabular}{|c|l|c|}
\hline No & \multicolumn{1}{|c|}{ Manfaat Tidak Berwujud } & Total \\
\hline 1 & Peningkatan produktivitas karyawan & Rp. $183.600 .000,--$ \\
\hline 2 & Peningkatan moral kerja karyawan & Rp. $37.800 .000,-$ \\
\hline \multicolumn{2}{|l|}{ Total } & Rp. 221.400.000,-- \\
\hline
\end{tabular}

Total manfaat berwujud dan tidak berwujud yang telah dihitung adalah sebesar Rp. 337.742.000,-. Pada tahun berikutnya mengalami kenaikan 5\% tiap tahun. Nilai 5\% mengacu pada kenaikan inflasi pada bulan Januari 2013 hingga Nopember 2015 yang berkisar 5\% per tahun. Tabel 7 menjelaskan total manfaat berwujud dan tidak berwujud untuk 5 tahun kedepan:

Tabel 7 Total Manfaat selama 5 Tahun

\begin{tabular}{|c|c|}
\hline \multirow{2}{*}{ Tahun } & Nilai Manfaat (Rp) \\
\cline { 2 - 2 } & $\mathbf{5 \%}$ \\
\hline 1 & Rp. 337.742.000,- \\
\hline 2 & Rp. 354.629.100,- \\
\hline 3 & Rp. 372.360.555,- \\
\hline 4 & Rp. 390.978.583,- \\
\hline 5 & Rp. 410.527.512,- \\
\hline
\end{tabular}

L-2 Evaluasi Investasi Teknologi Informasi M enggunakan Metode Cost and Benefit Analysis (Heni Sulistiani) 


\subsection{Perhitungan Analisis Biaya dan Manfaat}

Analisis biaya dan manfaat yang telah dilakukan pada bagian sebelumnya akan digunakan sebagai masukan dalam perhitungan keuangan. Perhitungan keuangan ini digunakan untuk menilai apakah investasi aplikasi project management layak jika dilihat secara ekonomi. Metode perhitungan yang digunakan adalah Net Present Value (NPV). Metode ini merupakan metode yang memperhatikan nilai waktu dari uang dan menggunakan suku bunga diskonto yang akan mempengaruhi cash inflow atau arus dari uang. Dalam metode ini, satu rupiah nilai uang sekarang lebih berharga dari satu rupiah nilai uang kemudian hari, karena uang tersebut dapat diinvestasikan atau ditabung dalam jangka waktu tertentu dan akan mendapatkan keuntungan dari bunga. Net present value dapat dihitung dari selisih nilai proyek pada awal tahun dikurangi dengan tingkat bunga diskonto. Dengan menggunakan tingkat suku bunga sebesar $10 \%$ pertahun dan rumus persamaan NPV :

maka

$$
\mathrm{NPV}=- \text { nilai proyek }+\frac{\text { cash flow } 1}{(1+\mathrm{i})^{1}}+\frac{\text { cash flow } 2}{(1+\mathrm{i})^{2}}+\frac{\text { cash flow } \mathrm{n}}{(1+\mathrm{i})^{\mathrm{n}}}
$$

$$
\begin{aligned}
& N P V=-49.929 .000+\frac{135.142 .000}{(1+0,10)^{1}}+\frac{143.029 .100}{(1+0,10)^{2}}+\frac{150.180 .555}{(1+0,10)^{3}}+\frac{157.689 .583}{(1+0,10)^{4}} \\
& N P V=-49.929 .000+\frac{135.142 .000}{1,10}+\frac{143.029 .100}{1,21}+\frac{150.180 .555}{1,33}+\frac{157.689 .583}{1,46} \\
& N P V=-49.929 .000+122.856 .364+118.205 .868+112.832 .874+107.704 .107 \\
& N P V=411.670 .212
\end{aligned}
$$

Dari hasil perhitungan di atas diketahui bahwa nilai NPV untuk investasi aplikasi project management pada ARM Solusi adalah sebesar Rp. 411.670.212,-, ini berarti bahwa nilai NPV > 0, sehingga investasi aplikasi tersebut Layak.

\subsection{Analisis Kelayakan}

Berdasarkan hasil penelitian yang telah dilakukan, hasil identifikasi unsur biaya (cost) antara lain biaya pengadaan, biaya start up, biaya proyek dan biaya penerapan. Untuk unsur manfaat dibagi menjadi dua yaitu manfaat berwujud (tangible) dan manfaat tidak berwujud (intangible). Untuk manfaat berwujud dilakukn analisi menggunakan metode cost displacement, cost avoidance, decision analysis dan impact analysis. Sedangkan untuk manfaat tidak berwujud yang terdiri dari peningkatan motivasi karyawan dan peningkatan moral kerja karyawan, dilakukan analisis perhitungan dengan menggunakan penaksiran yang menetapkan persentase kemungkinan peningkatannya.

Pada penentuan nilai setiap unsur biaya dan manfaat dengan besaran nominal, diketahui bahwa total biaya yang dikeluarkan perusahaan pada tahun ke-0 adalah sebesar Rp. 49.929.000,- dan manfaat yang diperoleh perusahaan sebesar Rp. 337.742.000,-. Hal tersebut menunjukkan bahwa, total biaya lebih besar daripada total manfaat dengan selisih sbesar Rp. 287.813.000,-. Setelah dilakukan perhitungan keuangan untuk menilai apakah investasi aplikasi project management layak jika dilihat secara ekonomi menggunakan metode net present value, menghasilkan sebesar Rp. 411.670.212,-,. Hal tersebut berarti bahwa investasi untuk aplikasi project management layak diterapkan. Sesuai dengan ketentuan dari perhitungan NPV, jika nilai NPV $>0$ maka investasi akan menguntungkan sedangkan jika nilai NPV $<0$ maka investasi tidak menguntungkan.

\section{Simpulan}

Berdasarkan hasil penelitian yang teah dilakukan, maka dapat diambil kesimpulan:

a. Biaya yang dikeluarkan oleh perusahaan untuk membangun dan menjalankan aplikasi project management dibagi menjadi empat biaya, yaitu procurement cost, start up cost, project related cost dan ongoing cost.

b. Manfaat berwujud (tangible) yang diperoleh dari investasi aplikasi project management berasal dari total pendekatan cost displacement, cost avoidance, decision analysis dan impact analysis yaitu sebesar Rp. 116.342.000,-.

c. Manfaat tidak berwujud (intangible) yang diperoleh dari investasi aplikasi project management berasal dari peningkatan produktivitas karyawan, peningkatan moral kerja karyawan dengan total manfaat sebesar Rp. 221.400.000,-.

d. Perhitungan keuangan dengan menggunakan metode NPV menghasilkan nilai sebesar Rp. 411.670.212,-. Dari perhitungan tersebut nilai yang dihasilkan lebih dari nol, sehingga investasi aplikasi project management layak untuk diterapkan. 
Sebagai penelitian lebih lanjut, disarankan untuk melakukan perhitungan analisis biaya dan menfaat tidak hanya menggunakan metode net present value (NPV) tetapi dapat menggunakan metode lainnya seperti metode Internal Rate of Return (IRR), Return of Investment (ROI), Profitability Index (PI) atau Payback Period (PP). Sehingga dapat dilakukan perbandingan terhadap metode-metode tersebut dalam menghasilkan suatu keputusan kelayakan suatu teknologi informasi di suatu perusahaan.

\section{Daftar Pustaka}

[1] Sholiq, \& Shabrina, A. N. Analisis Kelayakan Investasi Apikasi Point of Sale pada Toko Grosir dan Ecer dengan Cost Benefit Analysis (Studi Kasus: Toko Nirwana Pamekasan). SNASTI. 2013; 17 - 30.

[2] Suherman, Siregar, H., \& Putri, A. D. Strategi Investasi Teknologi Informasi E-Procurement pada Lampung Utara dengan Menggunakan Cost/Benefit Analysis (Studi Kasus Unit Layanan Pengadaan (ULP) dan Dinas Pendapatan Pengelolaan Keuangan dan Aset (DPPKA)). Universitas Bina Nusantara. 2012.

[3] Julia, Chrisna \& Sitorus, Palti MT. Pengukuran Benefit Investasi Teknologi Informasi Menggunakan Metode Information Economics (Studi Kasus di PT Telekomunikasi Indonesia, Tbk). Jurnal Manajemen Indonesia. 2013; Vol. 12 - 4: 265 - 282.

[4] Apriliya, Rahadian, et al. Analisis Kelayakan Teknologi Informasi Menggunakan Metode Cost Benefit Analysis dengan Microsoft Excel. 2013; Universitas Sebelas Maret

[5] Hendarti, H., Nugroho, A. A., Legiastuti, D., \& Nikmah. Analisis Investasi Sistem Informasi dengan Menggunakan Metode Information Economics (Studi Kasus: PT Nasa). Seminar Nasional Teknologi Informasi (SNATI). 2011; 106 - 111.

[6] Prabantoro, G. Mengukur Kelayakan Ekonomis Proyek Sistem Informasi Manajemen Menggunakan Metode 'Cost \& Benefit Analysis' dan Aplikasinya dengan Ms Excel 2000. 2003; 1 - 14. 